\title{
Donor Support and the Impacts on Health System Strengthening in Sub-Saharan Africa: Assessing the Evidence through a Review of the Literature
}

\author{
Ufuoma Ejughemre* \\ Department of Community Medicine, Delta State University Teaching Hospital, Oghara, Delta State, Nigeria \\ *Corresponding author: ufuoma83@gmail.com
}

Received June 11, 2013; Revised June 28, 2013; Accepted June 30, 2013

\begin{abstract}
The signing of the United Nations millennium development goals created a platform for the injection of billions of dollars of donor funds into countries with great need. As it were, this funding is meant to accelerate the achievement of these goals by the year 2015 considering that amongst others, they will help in improving healthcare delivery and strengthen health systems. Of particular concern is the situation in sub-Saharan Africa. So far, the impact of donor support in the region has being fairly remarkable with funding to combat major health problems reaching unprecedented levels in recent times with improvements on certain fronts. However, reports have it that besides other issues in many instances funds are allocated only to disease specific projects ("vertical programming") rather than to broad based investments ("horizontal programming"). Furthermore, the problem of corruption and mismanagement of these funds in many of the recipient countries are bothering issues warranting urgent solutions. As these issues do come to bear, it is critical to state that donor support is only a part of the development picture. There is now the need for sustainable policies for gradually exiting from donor funding for health, without which these countries dependant on humanitarian actors, will continue to cripple their ability to be self-sufficient and self reliant, and should these agencies cease to continue or run out of funding the consequences for the region are dire.
\end{abstract}

Keywords: sub-Saharan Africa, donor support, health systems, sustainability

Cite This Article: Ejughemre, Ufuoma, "Donor Support and the Impacts on Health System Strengthening In Sub-Saharan Africa: Assessing the Evidence through a Review of the Literature." American Journal of Public Health Research 1, no. 7 (2013): 145-151. doi: 10.12691/ajphr-1-7-1.

\section{Introduction}

In September 2000, an agreement that saw member states of the United Nations sign the Millennium Development Goals (UNMDGs) was reached [1,2]. These are a set of eight international developmental targets intended to catalyse development, reduce global poverty and improve on the living standards of humans the world over [2]. Consequent to the signing of the UNMDGs, a platform was created for the injection of donor funds to countries with great need. This was to accelerate achieving the targets by the year 2015 [3]. Although, current estimates suggest that many countries are on track in implementing these goals, as they will considerably help in strengthening health systems and improve on healthcare delivery, to date progress towards these goals has not been as promising [3]. Of particular concern is the situation in Sub-Saharan Africa, where there have been concerted efforts through donor funding to improve on health care delivery and health outcomes $[4,5,6]$. Moreover, these developmental assistance in the region are to augment existing efforts in reducing under five mortality rates by reducing two thirds of the current under-five mortality, reduce maternal mortality rates by $75 \%$ as well as combating the perennial issues of HIV/AIDS, malaria and other diseases by halving and subsequently reversing the incidence of malaria and other major diseases by 2015 [7,8,9].

As it were, it is without much argument that the impact of donor support for health systems strengthening in SubSaharan Africa has being quite remarkable with funding reaching unprecedented levels and improvements on certain fronts $[4,5,6,10]$. These have led to developments within the health sector; in many instances primary health care services have been improved and health systems have been strengthened $[5,6]$. Interestingly, many countries in the region now rely heavily on the availability of donor grants and loans particularly to finance health care delivery with evidence showing that about $20 \%$ of the total health expenditure in about $48 \%$ of the 46 countries in the World Health Organization (WHO) African region is provided for by external sources- such as the United Nations agencies and other non-governmental agencies [11]. In spite of the increasing volumes of official development assistance being directed particularly at improving health care delivery and overall health systems performance in the region there have been reports of challenges. 
What is of critical concern is that not all the donor support targeted at improving healthcare delivery is reaching communities with the greatest need or being delivered in a manner that is proving effective $[3,12,13]$. For example, while aids for HIV/AIDS and health infrastructure have been used to strengthen health systems, and in some cases primary health care services have been improved, overall, there are reports of concerns, too among them, a temporal association between increasing HIV/AIDS funding and stagnant funding for reproductive health, and accusations that scarce personnel are siphoned off from other health care services by offers of betterpaying jobs in HIV/AIDS programs $[5,14,15]$. There are also concerns that donor expenditures in the region are not only unsustainable but may be considered as inadequate considering the enormous health care burden in the region [16]. Furthermore, there is an increasing controversy about whether the scaled-up investment in programs to strengthen the existing fragile health systems of many developing countries is producing the 'required outcomes' in creating self reliance in the benefiting countries [16]. In fact, some critics of donor support are of the view that many governments in the region have abdicated their primary responsibilities to donor partners [16]. These gamut of issues as well as the changing geopolitical climate of the recent past decade alongside the poor results of decades of work and billions of dollars targeted at improving social and economic conditions in the region led to critical questions being asked of the usefulness, impact and effectiveness of these donor support [3]. To this end, these questions culminated in a series of past high-level fora to debate the provision of aids and its management. Of these includes: The Monterrey Consensus of the International Conference on Financing for Development, the Joint Marrakech Memorandum, the Accra Agenda for Action and the Paris Declaration on aids effectiveness [3]. The rationale for these principles is that the provision, management as well as the use of aids should lead to better results in terms of achieving the development objectives set out in national development plans of which health policies forms a crucial objective, and the implications of these through a critical analytic review comes to bear.

\section{The Issues}

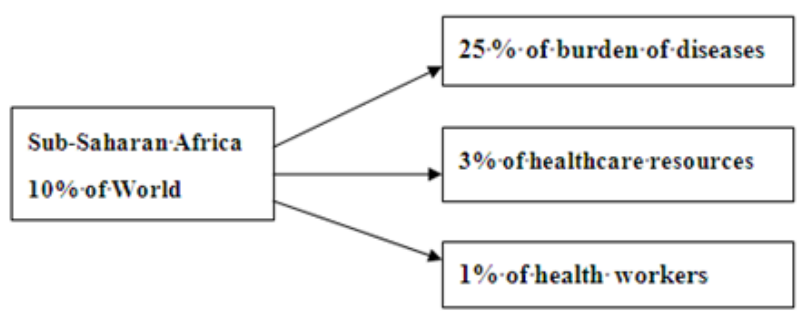

Figure 1. Burden of health and resources in the poorest continent. From Crisp N. (2010): Health and Poverty

As it were, the region is characteristically the poorest in the world and as illustrated in Figure 1 above, SubSaharan Africa has only 3\% of the world's health expenditure and $1 \%$ of the world's health workers to cope with $24 \%$ of the world's burden of diseases [17]. The starting point here is that funding for healthcare delivery is very low and as such poses a huge threat to achieving the targets of the MDGs. It is these issues that have necessitated the perennial injections of billions of dollars of donor funds to accelerate achieving the health targets of the UNMDGs particularly. To this end, there is no doubt that donor support over the years has had significant strides in improving on health systems performance in many parts of the region. As it were, these culminated in scaling up health care delivery and particularly improving the developmental trajectories in health systems in the region in the past few years to just over a decade $[4,5,6]$. However, a number of issues of critical concern to health policy makers in the region, donor institutions and governments include: funding, utilization and impact, as well as sustainability of donor support if the objectives of these international developmental assistance are anything to go by in Sub-Saharan Africa.

\subsection{Funding}

Following the signing of the millennium development goals in the year 2000 there have being the injection of tens of billions of dollars into Sub-Saharan Africa. The region alone receives a greater share, at 36\%, of total global aid than any other part of the world [18]. Statistical evidence shows that over the past four decades, aid to Africa has quadrupled from around US\$11 billion to US $\$ 44$ billion with a net increase of almost US $\$ 10$ billion during the years 2005-2008 and there have been an accelerated pace of donor support to Sub-saharan Africa in particular, which is a direct result of commitments made by the world's major aid donors and United Nations summits to the region [18]. Of critical concern is that substantial amount of these funds are channelled to fight issues bothering around health care delivery. Annually, sky rocket propelling sums of funds in billions of dollars are being transfused into the region to ameliorate the health care challenges which are critical to the achieving the UNMDGs particularly goals 4, 5, 6 [19,20]. For instance, between the year 1997 and 2002, donor support to improve health care in the region and other developing countries increased by about 26\%, from US\$6.4bn (£3.3m; $€ 4.4 \mathrm{~m})$ to $\$ 8.1 \mathrm{bn}$ [21]. More so, evidence shows that donor funding for HIV programs doubled as a proportion of all developmental assistance for health from 2000 to 2007, and HIV aid increased nearly tenfold from 1992 to 2005 [19,21]. Additionally, financial revelations from the World Bank estimates that in 2007 alone it had disbursed over US\$405million, including funds for direct projects and lending for AIDS prevention and control in the region [22] and these figures have been on the increase five years counting. Reports from the World Health Organization (WHO) macroeconomics commission estimated that in the year 2004 the WHO African region total health expenditure was approximately US\$ 35.53 billion, of which approximately US\$2.23 billion (6.25\%) was from external sources $[23,24]$. The report has it that external funding on health as a percentage of total health expenditure varies between countries. Analysis from this document showed that 18 countries received less than $11 \%$ of their total health expenditure from external sources; 9 countries received 11-20\%; 7 countries received 21-30\%; 6 countries received $31-40 \%$; and the remaining 6 countries received $41-60 \%$ of their total 
health expenditure from external sources [23]. A closer look at the region shows that in 2005, Mozambique's total health expenditure was $\$ 356 \mathrm{~m}$ while foreign assistance accounted for US\$243m [25]. Similarly, Zambia's entire Ministry of Health budget for 2006 was a paltry sum of US\$136m with the President's Emergency Plan for AIDS Relief (PEPFAR) providing the country with a budget of US\$150m for tackling HIV/AIDS [26]. In fact since the onset of the programme, PEPFAR funding to some recipient countries neared or exceeded those countries entire national health budgets [26]. By 2009 PEPFAR accounted for approximately 70 percent of all HIV donor support in the region [21]. This unbalanced distribution of health funding occurs across Sub-Saharan Africa. More so in Nigeria alone, donor grants through the Global Funds for AIDS, Tuberculosis (T.B) and Malaria (GFTAM), amounting to US\$682,149,515, were provided between 2003 and 2009 [27]. Additionally, recent proposals by the World Health Organization projects that approximately US\$4.1billion is already earmarked to combat T.B and multidrug resistant tuberculosis (MDRTB) with an already existing gap of US\$1.6billion in low and middle income countries globally of which Sub-saharan Africa will consume the bulk of this funds when made available [28].

Besides increased funding for the major communicable diseases (HIV/AIDS, Tuberculosis and Malaria) in the region, there are also international donations and sometimes grants or loans for other health care challenges. In recent times, there have being scaling up of funds for the neglected tropical diseases in the region particularly through non-governmental organizations (NGOs). Of such is the Carter foundation that has funded the fight against dracunculiasis (guinea worm infection), trachoma control, river blindness, schistosomiasis control and lymphatic filariasis elimination [29]. Annually, these NGOs fund, mobilize as well as train workers in order to achieve their objectives in the region. Staggered estimates from reports have it that USD\$2-3 billion have being earmarked for the control of neglected diseases globally over the next three to five years with Sub-saharan Africa expected to gulp the lion's share [30]. Additionally, there are also scattered anecdotal reports of huge sums injected into health systems in the region for research and training and exact estimates are however difficult to ascertain. All these gives further insight into the enormous amount of funds poured into health systems and healthcare delivery in the region. It could then be well said that countries in the SubSaharan Africa rely so heavily on international grants, with its leaders 'prostrating' at often times in order to receive juicy slices of donor support for healthcare delivery on an annual basis.

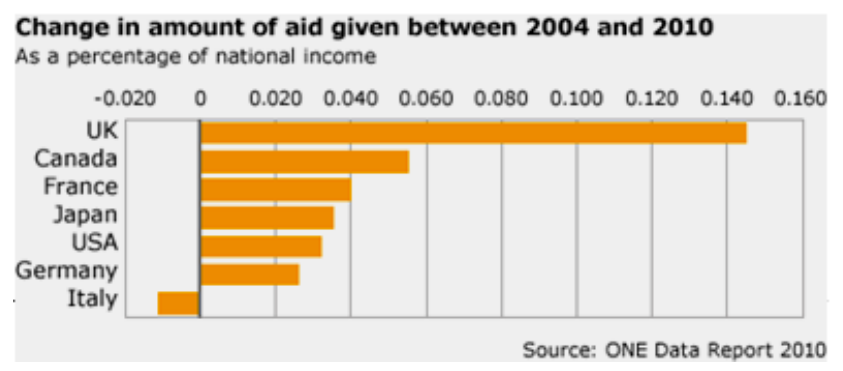

Figure 2. showing changes in amount of aids to Africa as a percentage of national income of G7 countries between 2004 -2010. Derived from ONE Data Report, 2010
As these issues do come to bear, a closer look at Figure 2 above shows a summary of the official developmental assistance to the African region. As it were, the report reveals that in 2005 developed nations known as the G7 (group of seven rich nations) agreed to "an increase in official development assistance to Africa of \$25bn [£17bn] a year by 2010, more than doubling aid to Africa compared to 2004 [31]. Although, fulfilling of this financial covenants have so far varied by these rich nations, what is obtainable is the fact that within the said period of six (6) years funds remitted to Africa as a percentage of national gross domestic product (GDP) of these countries increased annually. These findings are congruent with the evidence and assertion(s) that donor aids particularly those aimed at improving health care delivery in the region has increased over the years. Considering this and other global commitments towards the region, it then calls for a rapt attention on the utilization and impact of these huge sums of monies for improving on health care delivery and overall health systems in Sub-Saharan Africa.

\subsection{Utilization and Impact}

As international developmental funding for health care delivery has being consistent in the region hitherto; however, there are concerns about the utilization of these funds in many parts of the region. While these funds may be channelled for the their primary objective(s), aids in many instances are allocated only to disease specific projects (termed "vertical programming") rather than to broad based investments in health infrastructure, human resources, and community oriented primary healthcare services ("horizontal programming") [32]. The Zambian experience is an example that occurs across health systems in the region. Although, PEPFAR funding for HIV/AIDS in Zambia provides HIV positive patients free care, others with more routine diseases receive poor care and still have to pay. The situation is also such that salaries of healthcare providers working for donor funded vertical programmes are often more than double those of equally trained government workers in the fragile public health sector [33]. The import is that it lures highly skilled government workers to the higher paying vertical programmes and creates an internal 'brain drain'. This creates dire circumstances for the underfunded primary care clinics and health centres that care for all diseases, including common illnesses such as diarrhoea, poor nutrition and respiratory tract infections, which take many more lives than HIV/AIDS, tuberculosis, and malaria. In fact, these donor investments may shift strategies and commitments to manage other diseases in a country. It is not out of context to then ask if door funding has strengthened the health care system of recipient countries. Contrary to this view, advocates of donor funding believe that these funding such as that in Rwanda has improved the infrastructure, management, communications, laboratories, information systems, and human resources as well as contributed to standardization of services, strengthened monitoring and surveillance systems of health systems [33-35]. However, while these proponents of donor funds make grand claims about its achievements and potential in Rwanda, an overview of the literature reveals that this evidence is little to support these claims if other 
contextual issues- such as those of vertical funding, social and political factors- within the different countries in the region are taken into cognizance. This is largely due to the fact that it is very difficult to get a holistic evaluation of the impacts of donor funding.

Also, of cardinal concern is the issue of misappropriation and corruption. While aids may be allocated and in many instances 'sufficient', there is the challenge of misappropriation either by officials of recipient countries or due to systematic challenges causing waste. Corruption as it were is straightforward and it captures the extent and nature of the actions among officials-including bribes among civil servants, irregularities in public purchasing and oversight. It is the misuse of entrusted power for personal (pecuniary or monetary) gain [37]. Corruption as it were reduces the resources available for health development, lowers the quality of services, compromises effective coverage of health services and inflates the unit costs of services provided [36,37]. The problem with corruption and the lack of concern for basic principles in health care delivery is that well-intentioned spending such as those from international donations may have less than expected impact in health systems [38]. It is well said that “"priorities cannot be met if institutions don't function and scarce resources are wasted"' [38]. There are the situations where funds for projects were not even used and were 'siphoned' into private pockets with little or nothing to show in terms of health outcomes. In other instances, reports from findings that have probed the issue of supply management have emerged with the view that lack of drugs has been repeatedly shown to discourage utilization of public facilities even when there were donations from international agencies [37,38]. Evidence shows that a common practice in health centres in the region is that drugs tend to be a commonly "leaked" product given that it can fetch a higher price in the private market $[39,40]$. Surveys from Uganda reveals that the average leakage rate for drugs was estimated at $73 \%$ across 10 public health facilities with high demand drugs, such as those to treat malaria being the least available to patients because health workers and the health unit management committee members, the entities meant to provide local oversight, expropriated them [41]. These salient actions results in decreased utility (satisfaction) in economic terms and otherwise both to the funding agencies and the benefiting populace. Often times these have triggered remarks from donor countries and bilateral donor organizations to cut or withhold developmental assistance following developments that offends their driving principles as they will want to shield themselves from accusations of excessive meddling and from assuming responsibility for any failures or suboptimal outcomes. In fact, corruption and mismanagement of funds reduce the impact of donor funding for health system strengthening besides the challenge of vertical programmes being run by many donor agencies.

\subsection{Sustainability and the Future}

While developmental assistance may be of substantial support to health systems in sub-saharan Africa towards achieving the objectives the United Nations' millennium development goals, sustainability as it were is fundamental if anything is to go by. Beyond the millennium development goals, the region needs a post2015 development framework that reflects sustainability for health system strengthening besides donor assistance. This is because, given the existing issues surrounding the outcomes of donor support (corruption, vertical programmes, conflicts of interests' etc) for strengthening of health systems, it has become critical that countries of the region ought to implement strategies (bold steps to provide sustainable policies and workable programmes) for gradually exiting from donor funding for health [42]. This in no doubt supports the principle of self reliance of the World Health Organization [43].

Although, there is the view hitherto that these donor assistance for health care delivery in Sub-saharan Africa are providing sustainable programmes, the issue is that these programmes are hugely dependent on funds from their sponsors. The import being that in the event of cessation of funding for these 'workable' and 'sustainable' developmental programmes, the consequences for health systems in the region will be dire. Issues such as these do necessitate strategies to secure the future of the already donor-over-reliant health systems in the region. Workable and sustainable health policies will include: (i.) a decrease in economic inefficiencies (ii.) reprioritizing public expenditures (iii.) increasing additional tax revenues (iv.) increased private sector participation in health development and (iv.) fighting corruption [11].

In furtherance to achieving sustainability in this regards, efficiency in health systems is now an issue of critical concern. As it were, it is about producing the maximum health services from available quantity of health system inputs, using cost-minimizing production techniques as it substantiates the output from the use of a given quantity in terms of inputs [11]. Of note is the fact that there are reports of waste form inefficiencies in some of these programmes such as those funding vertical programmes [35]. Substantial evidence from a review of health facility efficiency studies in the WHO African Region have provided significant scope for increasing provision of health services using their current levels of resources allocated to hospitals and health centres [11]. Drawing from this, a health policy that will entail the leveraging of health promotion strategies to create the demand of underutilized healthcare or transferring specific inputs from over resourced to under resourced health facilities will be needful in this regards as it will reduce the inefficiencies (allocative inefficiencies) in many of these funded programmes [44]. More so, are the issues of inefficiencies arising from misallocation of resources such as the choice of a health facility site that is based on political criteria rather than need as well as funding of a programme where investments of the majority of resources are put into tertiary and secondary hospitals instead of in cost-effective primary health care or in situations where donor funds are channelled through vertical programmes instead of through the national health systems [45,46]. Answers to these will involve making investment decisions based on cost-effectiveness and costbenefit analysis criteria. Economic monitoring and evaluation through information systems in health systems across the region will also be critical to reduce waste of scare resources [47].

Furthermore, raising additional local revenue for health care delivery and increased private sector involvement in 
providing quality and equitable health services will be cardinal for these donor over-reliant health systems in Sub-Saharan Africa. Interestingly, the private sector already plays a very significant role in health service provision, financing (approximately 52\% of health expenditure), production of health inputs (such as medicines, health technologies and human resources) and construction of health infrastructure [11,45]. A report from the World Bank has it that private sector contributions in the region can be developed by enabling policy and regulatory frameworks, enforcing quality standards, expanding contributory arrangements through pre-payment schemes, contracting the private sector to deliver specific services, and improving the ability of the local financial institutions to support health service enterprises [48].

Additionally, sustainable and workable policies will only come to bear when corruption as it were in the systems are addressed meaningfully. Misappropriation of funds and other corrupt practices in funding, budgeting and expenditure, management of medical supplies and frictions in health worker/patient interaction can be brought to its barest minimum by providing sound institutional and legal frame works, developing of sound budget and expenditure systems and avoiding off-budget activities through effective auditing systems. More so, it is also of interest to add that the culture of corruption will require educating policy makers on health budgets and involving the mass media and civil society as channels to make information available for public scrutiny and appropriate channelling of all aid flows for health development [49]. Finally, it has to be stated clearly that there is no other solution to these problems, but for the effective management of external resources which will depend on addressing systemic inefficiencies, within donor and recipient environments.

\section{Conclusion}

As global commitments to improving on healthcare delivery in Sub-Saharan Africa continues through partnerships that enable the region to realise its health care goals, there is the need to achieve much more if all countries in the region are to meet the health targets of the millennium development goals. Donor support is only a part of the development picture. Economic growth and social progress as well as sustainable and workable policies for gradually exiting from donor funding for health is needful, without which these countries dependant on humanitarian actors will continue to cripple their ability to be self-sufficient and self reliant, and should these agencies cease to continue or run out of funding the consequences for the region are dire.

\section{Evidence for Review}

Literature reviews are summaries of research evidence that address research questions or issues by using explicit methods to identify, select, and critically appraise relevant research studies or documents, and to collect and analyse data from the studies that are included for the review. To this end, the author involved a broad search of literatures on donor aids in Sub-Saharan Africa. By using broad criteria the author made the review as inclusive as possible and online search engines and databases including PUBMED and Google Scholar were searched as well as grey literatures and hand searches of bibliographic records were done. Moreover, the author calls for further research, particularly through empirical studies in this regards to provide further insights on donor support from the technical reports of NGOs working in the region through regular publication.

\section{Author's Statement}

This paper clearly expresses the views of the author as there are no competing interests (financial or personal). For enquires on the views of this document please contact the author.

\section{Acknowledgement}

I give all gratitude to God Almighty for his inspiration and the suggestions of the anonymous peer reviewers.

\section{References}

[1] The United Nations General Assembly Session 55, Meeting 3. $6^{\text {th }}$ September, 2000.

[2] United Nations Summit Agenda; The largest gathering of world leaders in history meets in New York to discuss the role of the United Nations in the 21st century.". BBC News. $7^{\text {th }}$ December, 2000. Retrieved $22^{\text {nd }}$ November, 2006.

[3] Hayman, R., Taylor, E.M., Crawford, F., Jeffery, P., Smith, J., Harper, I. The impact of aid on maternal and reproductive health. A systematic review to evaluate the effect of aid on the outcomes of Millennium Development Goal 5. London: 2011. EPPI-Centre, Social Science Research Unit, Institute of Education, University of London.

[4] Musango L. Impact of HIV Projects on Health Systems in Rwanda. 2007, Kigali, Rwanda.

[5] Yu D, Souteyran Y, Banda MA, Kaufman J, Perriëns JH. Investment in HIV/AIDS programs: Does it help strengthen health systems in developing countries? Globalization and Health 2008, 4:8.

[6] Kim, J.Y., Gilks, C.F: Scaling up treatment - why we can't wait. New England Journal of Medicine 2005, 353:2352-2354.

[7] United Nations Millennium Development Goal: Reduce Child Mortality". MDG Monitor. $5^{\text {th }}$ May, 2011. Retrieved $18^{\text {th }}$ October, 2012.

[8] United Nations Millennium Development Goal: Improve Maternal Health". MDG Monitor. Retrieved 18 ${ }^{\text {th }}$ October, 2012.

[9] United Nations Millennium Development Goal: Combat HIV/AIDS, Malaria and Other Diseases. MDG Monitor. Retrieved $18^{\text {th }}$ October, 2012.

[10] Bryan, L., Conway, M., Keesmat T., McKeena S., Richardson, B. A practical guide to Health System Strengthening in sub-Saharan Africa. Health International, 2009, pp1-3.

[11] Kirigia M.J, Diarra-Nama A. Can countries of the WHO African Region wean themselves off donor funding for health? Bulletin of the World Health Organization 2008;86:889-895.

[12] Greco, G., Powell-Jackson, T., Borghi, J., Mills, A. Countdown to 2015: Assessment of donor assistance to maternal, newborn, and child health between 2003 and 2006. The Lancet, 2008. 371: 1268-75.

[13] Powell-Jackson T, Borghi J, Mueller DH, Patouillard E, Mills A. Countdown to 2015: Tracking donor assistance to maternal, newborn, and child health. The Lancet 2006;368: 1077-87.

[14] Hsiao WC, 2007. Why is a systemic view of health financing necessary? Health Africa (Millwood) 26: 950-961. 
[15] Schieber, G., Gottret, P., Fleisher, L., Leive, A., 2007. Financing global health: mission unaccomplished. Health Aff 26: 921.

[16] Okungu V. Has health aid failed to mitigate out-of-pocket expenditure in developing countries? International Health Policies News. 2011. Available at < http://e.itg.be/ihp/archives/health-aidfailed-mitigate-out-of-pocket-expenditure-developing-countries/> Accessed $5^{\text {th }}$ May, 2013.

[17] World Health Organization. Working Together For Health. The World Health Report 2006.

[18] Aid to Africa, Policy Brief. 2010. Available Online at <http://www.un.org/africa/osaa/reports/2010_Aidbrief.pdf> Accessed 30th April, 2013.

[19] Leach-Kemon, K., Chou, D.P., Schneider, M.T., Tardif, A., Dieleman, J.L, Brooks, BP. The global financial crisis has led to a slowdown in growth of funding to improve health in many developing countries. Health Africa (Millwood). 2012; 31(1):22835.

[20] Shiffman, J. Has donor prioritization of HIV/AIDS displaced aid for other health issues? Health Policy and Planning. 2008;23(2):95-100.

[21] Grépin, K.A. Health Services In Sub-Saharan Africa HIV Donor Funding Has Both Boosted And Curbed The Delivery Of Different Non-HIV. Health Affairs, 2012; 31, no.7:1406-1414.

[22] The World Bank's Commitment to HIV/AIDS in Africa: Our Agenda for Action, 2007-2011,” World Bank, 2008.

[23] WHO Statistical Information System. Geneva: WHO 2008. Available Online < http://www.who.int/whosis/en/index.html> Accessed on $30^{\text {th }}$ September 2008.

[24] WHO Engaging for health. Eleventh General Programme of Work 2006-2015. 2006 Online , available at

<http://whqlibdoc.who.int/publications/2006/GPW_eng.pdf> Accessed 25 ${ }^{\text {th }}$ April, 2013.

[25] Martinez J. Implementing a sector wide approach in health: the case of Mozambique. 2006. Available at < www.hlspinstitute.org/files/project/100615/Mozambique_SWAP.p df $>$ Accessed $28^{\text {th }}$ April, 2013.

[26] Bernstein M, Sessions M. A. Trickle or a flood: commitments and disbursement for HIV/AIDS from the Global Fund, PEPFAR, and theWorld Bank's Multi-Country AIDS Program (MAP.Washington (DC): Center for Global Development and HIV/AIDS Monitor 2007.

[27] Information Nigeria. Available at < http://www.informationng.com/2011/11/donor-recipients-differover-n1-6b-aids-fund-for-nigeria.html $>2013$, Accessed $1^{\text {st }}$ May, 2013.

[28] World Health Organization Report. Tuberculosis financing and Funding Gaps. 2013. Online

< http://www.who.int/tb/WHO_GF_TB_financing_factsheet.pdf > Accessed $2^{\text {nd }}$ May, 2013.

[29] Carter Foundation 2013. Available at

< http://www.cartercenter.org/health/index.html $>$ Accessed $2^{\text {nd }}$ May, 2013.

[30] Hotez. P.J "How To Cure 1 Billion People? -- Defeat Neglected Tropical diseases". Scientific American. Retrieved $1^{\text {st }}$ January, 2010.
[31] BBC African News. Did more African aid deliver fewer coups? One Data Report, 2010. Available Online at $<$ http://www.bbc.co.uk/news/10148173> Accessed 27 $7^{\text {th }}$ June,2013

[32] Jan De Maeseneer et al. Strengthening primary care: addressing the disparity between vertical and horizontal investment. Br J Gen Pract. 2008 January 1; 58(546): 3-4.

[33] Musango, L. Impact des Projets de Lutte contre le VIH sur le Systeme de Sante' au Rwanda. 2007, Kigali, Rwanda.

[34] Price JE, Leslie JA, Welsh M, Binagwaho A, 2009. Integrating HIV clinical services into primary health care in Rwanda: a measure of quantitative effects. AIDS Care 21: 608-614.

[35] Delph, E. Global Vertical Programmes. The Future of Aid or a Quick Fix? Quezon City, the Philippines: EURODAD. 2008.

[36] Lewis, M. "Health and Corruption in Developing and Transition Countries”. Presented at the Transparency International Annual Conference, 2003. Seoul, Korea.

[37] Transparency International. Global corruption report 2006: corruption and health. London: Pluto Press.

[38] World Bank. 2005a. Doing Business in 2005: Removing Obstacles to Growth. Washington, D.C.: World Bank.

[39] Lewis, M. "Informal Health Payments in Central and Eastern Europe and the Former Soviet Union: Issues, Trends and Policy Implications" in Funding Health Care: Options for Europe. 2002. Figueres and Moussiales. editors. Buckingham: Open University Press.

[40] Lewis, M. Governance and Corruption in Public Health Care Systems. Working Paper2006. Pp. 21-22.

[41] McPake, B.,A. D. Asiimwe, F.Mwesigye, et. al. "Informal Economic Activities of Public Health Workers in Uganda: Implications for Quality and Accessibility of Care." Social Science and Medicine. 1999; 49: 849-865.

[42] Paris declaration on aid effectiveness: ownership, harmonization, alignment, results and mutual accountability. Paris: Organisation for Economic Co-operation and Development; 2005.

[43] World Health Organization "Declaration of Alma Ata: International Conference on Primary Health Care, Alma Ata, USSR 6-12 September, 1978”. Available at < www. who.int /hpr/NPH /docs /declaration_almaata.pdf $>$ Accessed $26^{\text {th }}$ June 2012.

[44] Kirigia, J.M., Emrouznejad, A., Cassoma, B., Asbu, E.Z., Barry, S.A. Performance assessment method for hospitals: the case of municipal hospitals in Angola. Journal of Medical Systems 2008.

[45] Gottret15. P, Schieber G. Health financing revisited: a practitioner's guide. Washington, DC: The World Bank; 2006.

[46] Health16. Financing: a strategy for the African Region. Brazzaville: WHO Regional Office for Africa; 2006.

[47] Renner, A., Kirigia, J. M., Zere, A.E., Barry, S.P., Kirigia, D.G., Kamara, C., Muthuri, HK. Technical efficiency of peripheral health units in Pujehun district of Sierra Leone: a DEA application. BMC Health Serv Res 2005;5:77.

[48] International Finance Corporation. The business of health in Africa: partnering with the private sector to improve people's lives. Washington, DC: The World Bank; 2008.

[49] Vian, T. Review of corruption in the health sector: theory, methods and interventions. Health Policy and Planning, 2008;23:83-94. 